\title{
Diffuse large B cell lymphoma evolving from extranodal marginal zone lymphoma as the first presentation of complicated coeliac disease: case report and review of the literature
}

\author{
Mireille J. Hardie • Isaac A. Thyer • Tindaro Giardina • \\ Michael A. Platten • Martin J. Hudson • Paul J. Drury • \\ Dominic Spagnolo
}

Received: 18 August 2011 /Accepted: 21 November 2011 /Published online: 22 December 2011

(C) Springer-Verlag 2011

\section{Introduction}

Complicated coeliac disease (CD) is known to predispose to enteropathy-associated T cell lymphoma (EATL) [1-3], but its association with an increased risk of $\mathrm{B}$ cell non-Hodgkin lymphoma (B-NHL) is not as well recognised [4]. Data on the association of B-NHL with CD are sparse, and the pathogenesis of $\mathrm{B}$ cell lymphoma in the context of $\mathrm{CD}$ remains unknown. It has been hypothesised that chronic $\mathrm{B}$ cell stimulation and antigenic drive play a role in lymphomagenesis. This occurs with chronic inflammation in the setting of Helicobacter pylori-associated extranodal marginal zone lymphoma and in a variety of autoimmune-related diseases. Hence, CD may favour the development of B-NHL in a

\author{
M. J. Hardie $(\bowtie) \cdot D$. Spagnolo \\ PathWest Laboratory Medicine, QEII Medical Centre; \\ and School of Pathology and Laboratory Medicine, \\ University of Western Australia, \\ Hospital Avenue, \\ Nedlands, WA, Australia \\ e-mail: mireille.hardie@gmail.com \\ I. A. Thyer \\ Urology Department, Royal Perth Hospital, \\ Wellington St, \\ East Perth, WA, Australia \\ M. J. Hudson · P. J. Drury \\ Geraldton Regional Hospital, \\ Shenton Street, \\ Geraldton, WA, Australia \\ T. Giardina $\cdot$ M. A. Platten \\ PathWest Laboratory Medicine, QEII Medical Centre, \\ Hospital Avenue, \\ Nedlands, WA, Australia
}

similar way. The incidence of B-NHL of the small intestine arising in previously undiagnosed $\mathrm{CD}$ appears to be very low with only a few previous similar cases reported in the literature [5, 6]. This case highlights the importance of considering underlying undiagnosed $\mathrm{CD}$ in young patients developing small intestinal B-NHL.

\section{Clinical history}

A 35-year-old male presented to the emergency department with a 4-day history of abdominal pain, nausea and vomiting but without fever, altered bowel habit or weight loss. Physical examination revealed a mildly distended abdomen with mild peri-umbilical and right upper quadrant tenderness without peritonism. Bowel sounds were high-pitched, and there were no palpable masses. Rectal examination was normal.

Laboratory tests revealed normal electrolytes, creatinine, liver enzymes, bilirubin, protein and lipase. Haemoglobin was $175 \mathrm{~g} / \mathrm{L}$, white cell count was $8.2 \times 10^{9} / \mathrm{L}$ and platelet count was $308 \times 10^{9} / \mathrm{L}$. The lymphocyte count was mildly depressed at $0.98 \times 10^{9} / \mathrm{L}$. Plain abdominal X-ray on admission showed extensive small bowel dilatation consistent with high-grade, mid-to-distal small bowel obstruction. Computed tomography scan of the abdomen with oral contrast showed a sausage-shaped filling defect in the proximal ileum suggesting either intussusception or a small bowel tumour. Mesenteric lymphadenopathy up to $12 \mathrm{~mm}$ was also noted.

At laparotomy, the small bowel was found to be markedly distended up to and including the proximal third of the ileum, at which point a small bowel tumour was found 
associated with induration of the small bowel serosa but without obvious extramural spread. There was mesenteric lymphadenopathy while the liver and spleen were normal. A $15-\mathrm{cm}$ segment of proximal ileum with associated mesentery was resected and an entero-enterostomy was formed.

Staging investigations included flow cytometry on a bone marrow aspirate specimen which did not show any monotypic lymphoid population. An initial positron emission tomographycomputed tomography (PET-CT) scan showed moderate diffusely increased uptake within multiple small bowel loops, suspicious for diffuse small bowel lymphoma, but there was no apparent lymph node or distant involvement.

The patient was treated with combination chemotherapy and Mabthera. A follow-up PET-CT demonstrated a significant interval improvement in the intensity of uptake within small bowel loops and still no activity in lymph nodes or above the diaphragm. At the time of this report, the patient is in remission from his lymphoma. A follow-up duodenal biopsy showed total villous atrophy despite adherence to a gluten free diet. The patient has refused to have tissue transglutaminase IgA levels tested.

\section{Materials and methods}

The specimen was received in formalin which limited the performance of ancillary studies. Tissue blocks were sampled and processed using standard methods. Sections were cut onto Superfrost plus slides, and immunohistochemistry was performed using a Ventana benchmark XT automated tissue processor.

Genomic deoxyribonucleic acid (DNA) was prepared from formalin-fixed paraffin-embedded tissues using standard procedures (ethanol/xylene de-paraffinisation, proteinase K digestion) and DNA extracted by affinity purification (QIAamp handbook, QIAGEN, Melbourne, Australia). Low-grade (mucosa-associated lymphoid tissue (MALT) lymphoma) and high-grade (diffuse large B cell lymphoma, DLBCL) components of the lymphoma were intermixed, and hence, it was not possible to accurately microdissect these areas separately for molecular analysis. Polymerase chain reaction (PCR) was performed on extracted genomic DNA using BIOMED-2 TCR-beta, TCR-gamma and IgH clonality assays according to standardised protocols (InVivoScribe Technologies, San Diego, CA, USA) [7, 8]. Fluorescently tagged PCR products were separated by capillary electrophoresis (ABI prism 3100 Genetic Analyzer; Applied Biosystems, Melbourne, Australia), and GeneScan plots were interpreted by PeakScanner software (version 1.0; ABI prism). All assays were performed in duplicate.

\section{Results}

Macroscopically, there was an area of constriction caused by diffuse white thickening of the ileal wall over a length of $15 \mathrm{~mm}$ associated with mucosal ulceration. The adjacent non-lesional small bowel mucosa appeared mildly flattened and oedematous. A few mesenteric lymph nodes with a normal gross appearance were identified.

Microscopically, a low-grade MALT lymphoma predominated, composed of a variably pleomorphic population of centrocyte-like cells also showing extensive plasmacytoid differentiation. Sheets of atypical lymphocytes were seen to replace the mucosa in a partly laminar fashion and infiltrated through submucosa, muscularis propria and into subserosa. Plasmacytoid lymphocytes and plasma cells contained frequent intranuclear Dutcher bodies and cytoplasmic Russell bodies. Scattered lymphoepithelial lesions were present in the mucosal component (Fig. 1a). There were prominent reactive lymphoid follicles occurring transmurally with extension into peri-ileal fat. Merging with this low-grade MALT lymphoma element, there was a minor component ( $\sim 20 \%$ ) of DLBCL composed of sheets of large centroblasts and immunoblasts (Fig. 2). Both lymphoma elements were CD20+ and BCL2+, while the plasma cell component was CD138+ and showed kappa light chain restriction (Fig. 1b). The MIB-1 proliferation index exceeded $70 \%$ in the DLBCL component. Negative stains included CD3, CD5, CD10, BCL6, CD23, CD30, cyclin D1, MUM-1 and lambda
Fig. 1 Low-grade MALT lymphoma component. a Lymphoepithelial lesion (haematoxylin and eosin, $\times 400$ ); inset combined AE1/AE3 (red) and CD20 (brown) immunostain, $\times 600)$. b The lymphoma shows kappa light chain restriction (kappa, $\times 400$ left and lamb$\mathrm{da}, \times 400$ right)

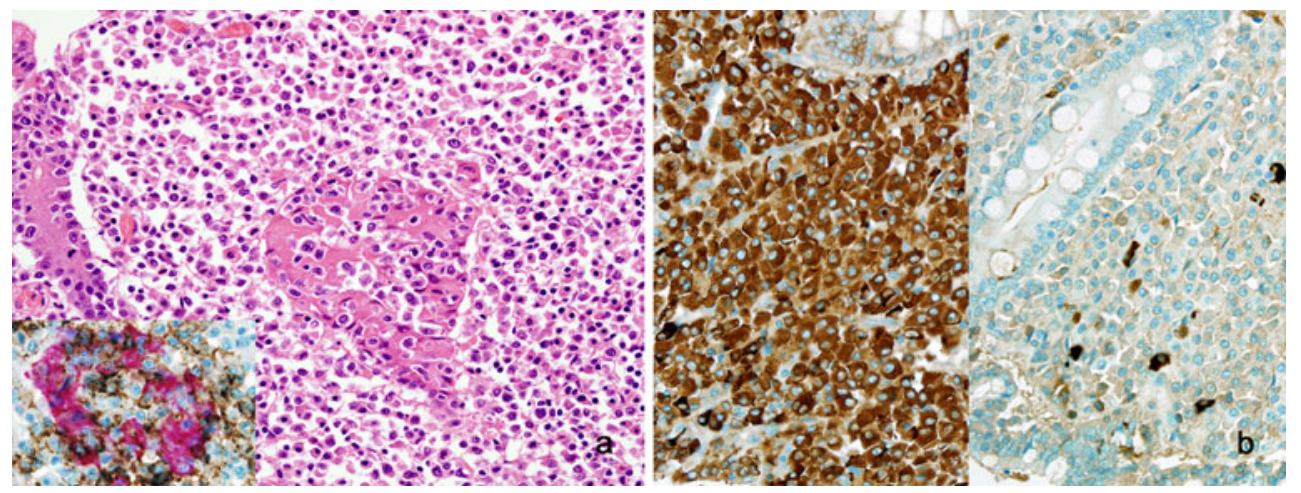




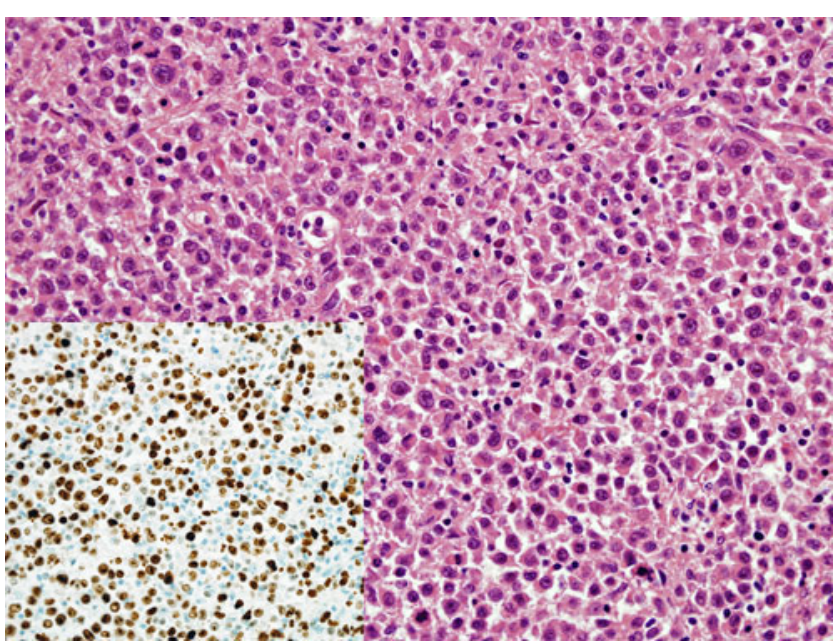

Fig. 2 DLBCL component with sheets of large centroblasts and immunoblasts (haematoxylin and eosin, $\times 400$ ); inset high proliferation index (MIB-1, $\times 400)$

light chain (plasma cell component). There was also a prominent infiltrate of reactive small $\mathrm{T}$ cells throughout. The regional lymph nodes did not show any lymphomatous involvement. There was no fresh tissue available for flow cytometry studies.

The mucosa adjacent to the tumour showed total crypt hyperplastic villous atrophy with markedly increased numbers of intraepithelial lymphocytes (Fig. 3a) causing distortion of the enterocytes consistent with underlying $\mathrm{CD}$. The immunophenotype of the intraepithelial lymphocytes was CD3, CD7 and CD8 positive (Fig. 3b) with partial loss of CD5. CD4 and CD56 were negative.

Antigen receptor gene rearrangement studies were carried out on DNA extracted separately from lymphomatous tissue and from the non-lymphomatous enteropathic mucosa. The lymphoma revealed monoclonal rearrangement of the $\operatorname{IgH}$ gene with peaks of 340, 276 and 133 nucleotides detected in the FR1, FR2 and FR3 assays (tubes A, B and C, respectively) (Fig. 4a). There was an indeterminate clonal rearrangement in the IgK assay, whilst only polyclonal TCRbeta and TCR-gamma gene rearrangements were detected here. It should be noted that there was no intact enteropathic mucosa included in the lymphomatous tissue examined. The adjacent (non-lymphomatous) enteropathic mucosa showed monoclonal rearrangements of the TCR-beta and TCRgamma genes indicating the presence of a monoclonal $\mathrm{T}$ cell population. There were peaks of 275 and 198 nucleotides detected in tubes $B(\mathrm{~V} \beta-\mathrm{J} \beta)$ and $C(\mathrm{D} \beta-\mathrm{J} \beta)$ of the TCR-beta assay and a peak of 213 nucleotides in a background of polyclonal rearrangements detected in tube A $(\mathrm{V} \gamma-\mathrm{J} \gamma)$ of the TCR-gamma assay (Fig. 4b). The dominant peak of 213 nucleotides in the TCR-gamma assay needs to be assessed in the context of all the molecular and pathological data for, in isolation, given the significant polyclonal background which is present, assigning monoclonality would be difficult. A prominent peak that is at least three times the amplitude of the third largest peak in the polyclonal background within the valid size range is consistent with a positive (clonal) peak [8]. This criterion is met if the 213 nucleotide peak is compared to the polyclonal products defined by the particular V-gamma/J-gamma segment usage, but likely not if all the polyclonal products are considered. However, as the peak was completely reproducible, recognising that there are varying primer annealing efficiencies, given the unequivocal, reproducible monoclonal TCR-beta gene rearrangements which are present and importantly in the light of all the clinical and pathological findings, we consider this to be consistent with a monoclonal TCRgamma gene rearrangement. These results indicate the presence of T cell monoclonality in the enteropathic mucosa and are consistent with complicated CD.

\section{Discussion}

There is an established relationship between $\mathrm{CD}$ and an increased risk for the development of a specific type of $\mathrm{T}$ cell lymphoma known as EATL [1-3] according to the World Health Organisation lymphoma classification [9]. Most EATL occur in patients with complicated or refractory $\mathrm{CD}$ of substantial duration [10]. There has recently been much research into the pathogenesis of $\mathrm{T}$ cell lymphoma

Fig. 3 a Enteropathic small bowel showing total crypt hyperplastic villous atrophy and increased numbers of intraepithelial lymphocytes (haematoxylin and eosin, $\times 200$ ). The intraepithelial lymphocytes are CD3 (CD3, ×200 left) and CD8 $(\mathrm{CD} 8, \times 200$ right $)$ positive
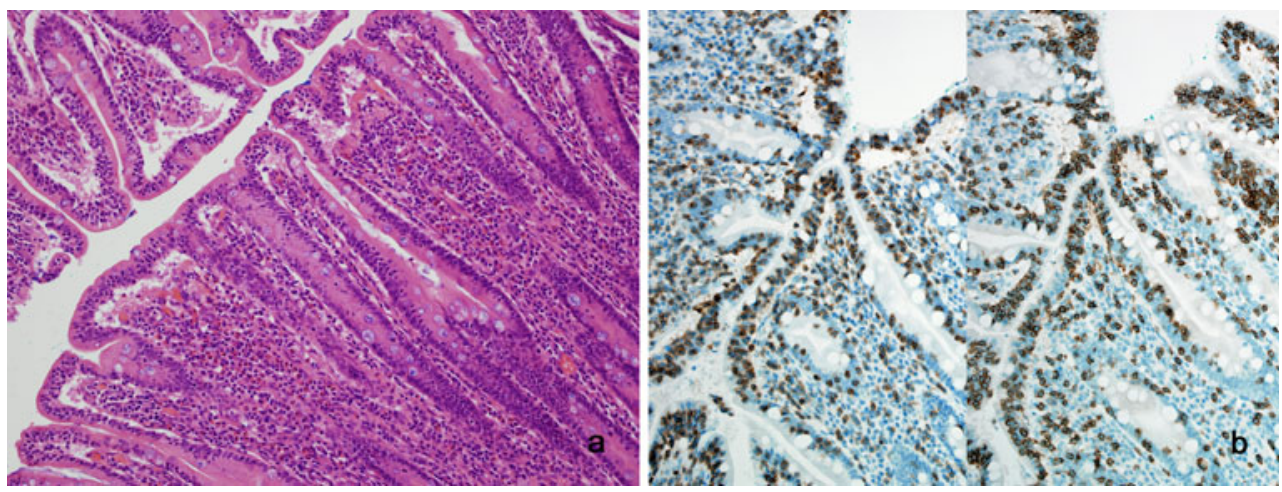


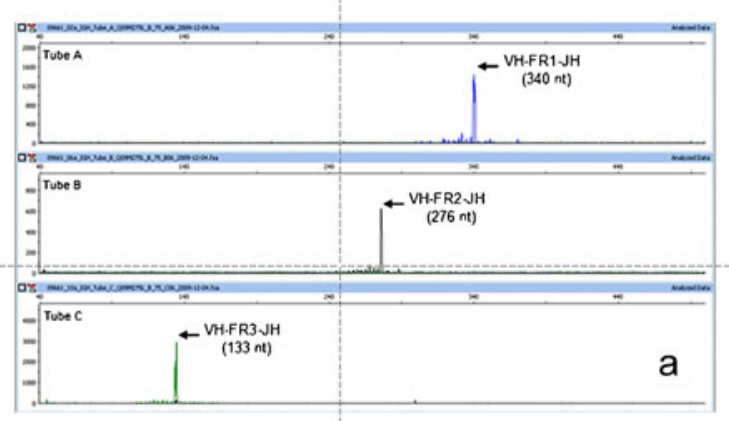

Fig. 4 a PCR performed on lymphomatous bowel revealed a monoclonal rearrangement of the IgH gene. b PCR performed on enteropathic mucosa revealed a monoclonal rearrangement of TCR-gamma

arising from intraepithelial lymphocytes with an aberrant immunophenotype in the setting of refractory CD [11]. In these so-called precursor lesions, the T cells may or may not show down-regulation of CD8 in addition to harbouring monoclonal rearrangements of the $\mathrm{T}$ cell receptor genes [9, 12], thus considered by some as representing in situ or "cryptic" T cell lymphomas [2, 13]. Identical clonal rearrangements may be found in EATL developing in this setting, thus establishing a direct relationship between refractory CD and EATL.

It is also known that patients with CD have an overall risk of cancer that is almost twice that in the general population [14], including an increased risk of B cell lymphomas [4, 15] with DLBCL being the most common lymphoma type [16]. The literature has shown conflicting results in regards to the relative incidence of both $\mathrm{T}$ and $\mathrm{B}$ cell lymphomas in CD. A recent large cohort study [4] reported that the incidence of $\mathrm{T}$ cell lymphomas was markedly lower than previously reported and that in fact most lymphomas complicating CD were not of the EATL type. This study also found that the majority of B cell lymphomas occurred in non-intestinal sites including bone marrow, skin, liver, pancreas and lung [4]. The biological mechanisms that underlie the association between $\mathrm{CD}$ (and other autoimmune conditions causing chronic inflammation) and B-NHL are largely unknown [17].

There is increasing evidence that the chronic inflammatory response in autoimmune conditions, associated with dysregulation and hyperreactivity of B cells, in conjunction with altered $\mathrm{T}$ cell control may lead to an increased risk of lymphoma [18]. CD and other autoimmune disorders associated with increased risk of B-NHL are all characterised by B cell proliferation and autoantibody production [19]. Hence, it is hypothesised that both the chronic B cell stimulation and antigenic drive play roles in autoimmunityrelated lymphomagenesis [20]. In this way, it has been suggested that B-NHL in CD is conceptually similar to parotid gland MALT lymphoma in Sjögren syndrome and gastric MALT lymphoma in the presence of $H$. pylori

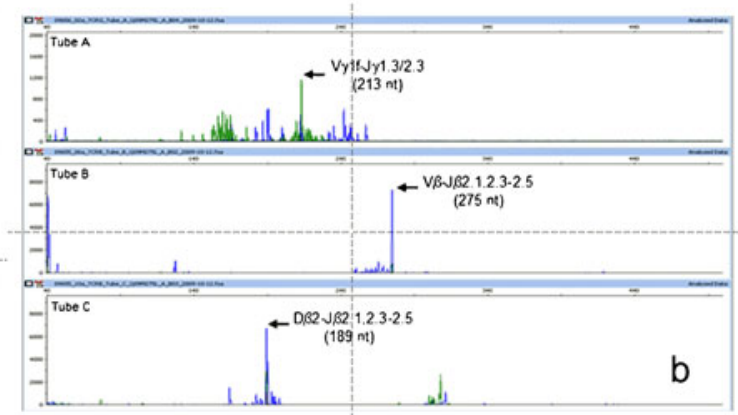

and TCR-beta genes. All assays were performed in duplicate and identical results were obtained

infection [21]. In gastric MALT lymphoma, Helicobacterspecific CD4+ T cells are generated which provide assistance for B cell activation and proliferation through CD40 signalling and Th2 cytokines [22]. These, together with direct antigen stimulation, may sustain the growth of the malignant B cells [23]. In CD, the gluten-reactive CD4+ T cells are central to the development of mucosal lesions; however, their possible role in the development of B-NHL is not yet completely understood.

Small intestinal B-NHL arising in undiagnosed CD remains a rare occurrence with only a few cases reported in the literature. Alcalde et al. [5] reported a case of a 35years-old female with a small bowel MALT lymphoma as the first presentation of CD. Makishima et al. [6] reported a case of a 65-years-old male with small bowel DLBCL, thought to be arising from a MALT lymphoma, again as the first presentation of CD. Neither of these case reports documented the immunophenotype and clonality of the $\mathrm{T}$ cell population in the enteropathic small bowel mucosa. The first reported case of metachronous EATL and DLBCL was published in 2007, where EATL and CD arose 6 years after the diagnosis of DLBCL of the small bowel [24]. This article postulated that this occurrence may have represented an unusual form of neoplastic transformation of a common pluripotent progenitor cell into two different lineages or that the two neoplastic clones may have risen independently.

The CD3+, CD7+ and CD8+ immunophenotype of intraepithelial lymphocytes is that usually seen in CD. Although an aberrant CD8 negative phenotype is that typically found in refractory $\mathrm{CD}$, some cases may be $\mathrm{CD} 8+$ and hence have the same phenotype as gluten-sensitive CD [12]. In these cases, molecular analysis for monoclonality of the $\mathrm{T}$ cell population is required to identify cases of refractory $\mathrm{CD}$ at risk of developing EATL.

Our case illustrates the need to consider and investigate for the possibility of underlying $\mathrm{CD}$ in cases of small bowel B-NHL. A current recommendation is for the measurement of tissue transglutaminase $\operatorname{IgA}$ levels in all patients with small intestinal B-NHL to exclude co-existent CD [25]. 
Unfortunately our patient refused to have this testing performed, but the immunophenotype and presence of clonal $\mathrm{T}$ cell receptor gene rearrangements in the enteropathic mucosa are fully consistent with underlying refractory CD. Investigation for an aberrant $\mathrm{T}$ cell immunophenotype as well as determining the presence of monoclonal $\mathrm{T}$ cell receptor gene rearrangements may also be important in regards to the risk of subsequent development of $\mathrm{T}$ cell lymphoma has implications for patient management and overall prognosis. The mechanism for the development of B-NHL of the small intestine from complicated $\mathrm{CD}$ remains unknown and further research is required in this area.

Conflict of interest The authors declare that they have no conflict of interest.

\section{References}

1. Loughran TP Jr, Kadin ME, Deeg HJ (1986) T-cell intestinal lymphoma associated with celiac sprue. Ann Intern Med 104:4447

2. Cellier C, Delabesse E, Helmer C, Patey N, Matuchansky C, Jabri B, Macintyre E, Cerf-Bensussan N, Brousse N (2000) Refractory sprue, coeliac disease, and enteropathy-associated T-cell lymphoma. Lancet 356:203-208

3. Smedby KE, Vajdic CM, Falster M et al (2008) Autoimmune disorders and risk of non-Hodgkin lymphoma subtypes: a pooled analysis within the InterLymph consortium. Blood 111:4029-4038

4. Smedby KE, Åkerman M, Hildebrand H, Glimelius B, Ekbom A, Askling J (2005) Malignant lymphomas in coeliac disease: evidence of increased risks for lymphoma types other than enteropathy-type T cell lymphoma. Gut 54:54-59

5. Alcalde M, Carro J, Rivero M, Fernandez JJ, Saenz De Santamaria J (1998) Malt lymphoma as first clinical presentation of celiac disease. Acta Gastro-Enterologica Belgica 61:479-482

6. Makishima H, Ito T, Kodama R, Asano N, Nakazawa H, Hirabayashi K, Nakamura S, Ota M, Akamatsu T, Kiyosawa K, Ishida F (2006) Intestinal diffuse large B-cell lymphoma associated with celiac disease: a Japanese case. Int J Hematol 83:63-65

7. van Dongen JJJM, Langerak AW, Bruggemann M, Evans PAS, Hummel M, Lavender FL, Delabesse E, Davi F, Schhring E, Garcia-Sanz R, van Krieken JHJM, Droese J, Gonzalez D, Bastard C, White HE, Spaargaren M, Gonzalez M, Parreira A, Smith JL, Morgan GJ, Kneba M, Macintyre EA (2003) Design and standardization of PCR primers and protocols for detection of clonal immunoglobulin and T-cell receptor gene recombinations in suspect lymphoproliferations: report of the BIOMED-2 Concerted Action BMH4-CT98-3936. Leukemia 17:2257-2296

8. InVivoScribe Technologies (2011) Identiclone TCRB clonality assay, TCRG clonality assay, TCRD clonality assay, IgH clonality assay, Ig-Kappa clonality assay and Ig-Lambda clonality assay. InVivoScribe Technologies, San Diego
9. Isaacson PG, Chott A, Ott G, Stein H (2008) Enteropathyassociated T-cell lymphoma. In: Swerdlow SH, Campo E, Harris NE, Jaffe ES, Pileri SA, Stein H, Thiele J, Vardiman JW (eds) WHO classification of tumours of haematopoietic and lymphoid tissues, 4th edn. International Agency for Research on Cancer, Lyon, pp 289-291

10. Pricolo VE, Mangi AA, Aswad B, Bland KI (1998) Gastrointestinal malignancies in patients with celiac sprue. Am J Surg 176:344 347

11. Ho-Yen C, Chang F, van der Walt J, Mitchell T, Ciclitira P (2009) Recent advances in refractory coeliac disease: a review. Histopathology 54:783-795

12. de Mascarel A, Belleannée G, Stanislas S, Merlio C, Parrens M, Laharie D, Dubus P, Merlio J (2008) Mucosal intraepithelial Tlymphocytes in refractory celiac disease: a neoplastic population with a variable CD8 phenotype. Am J Surg Pathol 32:744-751

13. Carbonnel F, Grollet-Bioul L, Brouet JC, Teilhac MF, Cosnes J, Angonin R, Deschaseaux M, Châtelet F, Gendre JP, Sigaux F (1998) Are complicated forms of celiac disease cryptic T-cell lymphomas? Blood 92:3879-3886

14. Green PHR, Cellier C (2007) Celiac disease. N Engl J Med 357:1731-1743

15. Mearin ML, Catassi C, Brousse N, Brand R, Collin P, Fabiani E, Schweizer JJ, Abuzakouk M, Szajewska H, Hallert C, Masip CF, Holmes GKT (2006) European multi-centre study on coeliac disease and non-Hodgkin lymphoma. Eur J Gastroenterology Hepatol 18:187-194

16. Catassi C, Fabiani E, Corrao G et al (2002) Risk of non-Hodgkin lymphoma in celiac disease. JAMA 287:1413-1419

17. Smedby KE, Hjalgrim H, Askling J, Chang ET, Gregersen H, Porwit-MacDonald A, Sundström C, Åkerman M, Melbye M, Glimelius B, Adami H (2006) Autoimmune and chronic inflammatory disorders and risk of non-Hodgkin lymphoma by subtype. $\mathrm{J}$ Natl Cancer Inst 98:51-60

18. Anderson LA, Gadalla S, Morton LM, Landgren O, Pfeiffer R, Warren JL, Berndt SI, Ricker W, Parsons R, Engels EA (2009) Population-based study of autoimmune conditions and the risk of specific lymphoid malignancies. Int J Cancer 125:398-405

19. Freitag T, Schultze-Koops H, Niedobitek G, Melino G, Schuppan D (2004) The role of the immune response against tissue transglutaminase in the pathogenesis of coeliac disease. Autoimmun Rev 3:13-20

20. Baecklund E, Askling J, Rosenquist R, Ekbom A, Klareskog L (2004) Rheumatoid arthritis and malignant lymphomas. Curr Opin Rheumatol 16:254-261

21. Burke JS (1999) Are there site-specific differences among the MALT lymphomas - morphologic, clinical? Am J Clin Pathol 111:S133-S143

22. Ferreri AJM, Ernberg JI, Copie-Bergman C (2009) Infectious agents and lymphoma development: molecular and clinical aspects. J Intern Med 265:421-438

23. Du MQ (2011) MALT lymphoma: many roads lead to nuclear factor- $\mathrm{kb}$ activation. Histopathology 58:26-38

24. Nava VE, Cohen P, Bishop M, Fowler D, Jaffe ES, Ozdemirli M (2007) Enteropathy-type T-cell lymphoma after intestinal diffuse large B-cell lymphoma. Am J Surg Pathol 31:476-480

25. Catassi C, Bearzi I, Holmes GK (2005) Association of celiac disease and intestinal lymphomas and other cancers. Gastroenterology 128:S79-86 